\title{
Estimated cancer burden attributable to the alcohol consumption in Poland in 2016
}

\author{
Paweł Koczkodaj, Urszula Sulkowska, Marta Mańczuk, Magdalena Cedzyńska, Irena Przepiórka, \\ Agata Ciuba, Krzysztof Przewoźniak, Joanna Didkowska
}

Department of Epidemiology and Cancer Prevention, Maria Skłodowska-Curie Institute - Oncology Center, Warsaw, Poland

Introduction. Alcohol exposure is a highly preventable cancer risk factor. European Code Against Cancer recommends to reduce alcohol intake of any type in order to decrease cancer risk. Poles have drunk more and more alcohol, reaching the average level of consumption at 9.55 liters of pure alcohol per capita in 2018. This phenomenon shows that alcohol consumption is constantly a great public health challenge in Poland.

Material and methods. Material in our study was an epidemiological data on cancer incidence in Poland sourced from the National Cancer Registry in Poland. Data on alcohol consumption comes from the State Agency for Prevention of Alcohol Related Problems survey conducted in Poland in 2002. Relative risks (RR) for alcohol consumption and cancer were sourced from the published studies. The alcohol attributable fraction (AAF) has been calculated with use of the formula provided in this work.

Results. Results of our study show that in Poland in 2016, about 4.6\% (7252) of all cancer cases were related to the alcohol consumption: women - 3.4\% (2599), men - 5.8\% (4653).

Conclusions. In the face of epidemiological prognosis on increasing number of new cancer cases in Poland, there is a need to implement an immediate public health actions on reducing strong cancer risk factors such as alcohol consumption.

NOWOTWORY J Oncol 2019; 69, 5-6: 179-181

Key words: cancer, alcohol, attributable fraction, primary cancer prevention

\section{Introduction}

In 1988 the International Agency for Research on Cancer (IARC) identified alcohol consumption as one of the strongest cancer risk factors [1]. Many scientific studies proved connection between alcohol consumption and occurrence of certain types of cancer. Currently, such connection is indicated most often for the following malignancies: lip, oral cavity and pharynx cancer, oesophagus, colon, rectum, liver, larynx and female breast cancer [2,3]. There is also some limited evidence suggesting that alcohol exposure is linked to cancers of gallbladder, prostate, lung, stomach and melanoma $[4,5]$.

Alcohol exposure is a highly preventable cancer risk factor. European Code Against Cancer recommends to reduce alcohol intake of any type in order to decrease cancer risk [3]. On the other hand, in accordance to the latest data from the State Agency for Prevention of Alcohol-Related Problems in Poland, during the last decades, Poles have drunk more and more alcohol, reaching the average level of consumption at 9.55 liters of pure alcohol per capita in 2018 [6]. This phenomenon shows that alcohol consumption is constantly a great public health challenge in Poland.

\section{Objectives}

The aim of the study was to estimate the number of cancer cases attributable to alcohol consumption in Poland in 2016.

\section{Material and methods}

Material in our study was an epidemiological data on cancer incidence in Poland in 2016 sourced from the National Cancer 
Registry in Poland (www.onkologia.org.pl). Data on alcohol consumption comes from the survey conducted by the State Agency for Prevention of Alcohol Related Problems in Poland in 2002 (data provided by J. Moskalewicz) [7]. We decided to use the data from 2002 in order to receive 15 years' latency period between the time of exposure and cancer occurrence, which is sufficient amount of time for developing alcohol attributable cancers. In the literature, chosen latency period varies, depending on many factors. Scientifically justified latency period ranges from 10 to 40 years $[2,8]$. Analyzed age group is $35+$ years, which is connected with exposure among people aged $20+$.

We set consumption categories as follows: 0 to $<0.25 \mathrm{~g} /$ day (abstainers); 0.25 to $<20 \mathrm{~g} /$ day; 20 to $<40 \mathrm{~g} /$ day; 40 to $<60 \mathrm{~g} /$ day and $\geq 60 \mathrm{~g} /$ day of pure alcohol. Relative risks (RR) for each category of alcohol consumption were sourced from Corrao 2004 et al. [9] for subsequent locations of cancers: lip, oral cavity and pharynx, oesophagus, colon, rectum, liver, larynx. In this publication authors presented RR for consumption of $25 \mathrm{~g} /$ day (used in our study for category 20 to $<40$ g/day), 50 g/day (applied for 40 to $<60 \mathrm{~g} /$ day) and $100 \mathrm{~g} /$ day (for category $60+$ $\mathrm{g} /$ day). For drinking category 0.25 to $<20 \mathrm{~g}$ /day we used risk as the half of that estimated for the $25 \mathrm{~g} /$ day. For female breast cancer we used RR from Hamajima et al. 2002 [10]. In this study authors showed that in comparison with women who were abstainers, drinking women had increased breast cancer risk by $7 \%$ for each additional $10 \mathrm{~g}$ of alcohol/day intake (Tab. I).
The alcohol attributable fraction (AAF) has been calculated according to the formula:

$$
A A F=\frac{\sum_{i=1}^{k} P_{i}\left(R R_{i}-1\right)}{\sum_{i=0}^{k} P_{i}\left(R R_{i}-1\right)+1}
$$

$i, k$ : category of drinking (with $i=0$ for abstainers)

$\mathrm{RR}_{i}$ : relative risk at the exposure level, i compared with abstainer category

$\mathrm{P}_{\text {: }}$ prevalence of alcohol, $i$-th category of exposure

\section{Results}

In accordance with the latest data from the National Cancer Registry in Poland, in 2016 over 164000 new cancer cases have been reported. In our study, we estimated that in this year 7252 cancer cases were related to the alcohol consumption: women - 3.4\% (2599), men - 5.8\% (4653) (Tab. II). The highest burden, in accordance to the location of the cancer, was connected with lip, oral cavity and pharynx cancers - 2493 cases. Moreover, a large number of all alcohol attributable cancer cases were identified as breast cancer cases - 1772 (Tab. II). Additionally, a significant number of alcohol-related cancer cases in our study were larynx cancer cases - 1011 - the vast majority cases occurred among men (938) than among women (73).

In relation to the age groups, the highest burden was observed among people aged 60-79 - 2821 cases in men and 1266 in women. Due to high alcohol consumption among

Table I. Relative risks for alcohol-attributable cancers by drinking categories

\begin{tabular}{|c|c|c|c|c|c|c|c|c|c|}
\hline \multirow[t]{2}{*}{ Cancer site } & \multicolumn{2}{|c|}{$\begin{array}{c}i=1 \\
0.25-<20 \mathrm{~g} / \text { day } \\
\end{array}$} & \multicolumn{2}{|c|}{$\begin{array}{c}i=2 \\
20-<40 \mathrm{~g} / \text { day }\end{array}$} & \multicolumn{2}{|c|}{$\begin{array}{c}i=3 \\
40-<60 \mathrm{~g} / \text { day } \\
\end{array}$} & \multicolumn{2}{|c|}{$\begin{array}{c}i=4 \\
60+\mathrm{g} / \text { day } \\
\end{array}$} & \multirow[t]{2}{*}{ Source } \\
\hline & M & $F$ & M & $F$ & $M$ & $\mathbf{F}$ & $M$ & $F$ & \\
\hline oral cavity, pharynx & 1.43 & 1.43 & 1.86 & 1.86 & 3.11 & 3.11 & 6.45 & 6.45 & Corrao 2004 \\
\hline esophagus & 1.19 & 1.19 & 1.39 & 1.39 & 1.93 & 1.93 & 3.59 & 3.59 & Corrao 2004 \\
\hline colon & 1.03 & 1.03 & 1.05 & 1.05 & 1.10 & 1.10 & 1.21 & 1.21 & Corrao 2004 \\
\hline rectum & 1.05 & 1.05 & 1.09 & 1.09 & 1.19 & 1.19 & 1.42 & 1.42 & Corrao 2004 \\
\hline liver & 1.09 & 1.09 & 1.19 & 1.19 & 1.40 & 1.40 & 1.81 & 1.81 & Corrao 2004 \\
\hline larynx & 1.22 & 1.22 & 1.43 & 1.43 & 2.02 & 2.02 & 3.86 & 3.86 & Corrao 2004 \\
\hline breast (female) & - & 1.09 & - & 1.18 & - & 1.35 & - & 1.70 & Hamajima et al., 2002 \\
\hline
\end{tabular}

Table II. Number of alcohol attributable cancer - cases by age groups

\begin{tabular}{|c|c|c|c|c|c|c|c|c|c|}
\hline \multirow[t]{2}{*}{ Cancer site } & \multicolumn{2}{|c|}{$\begin{array}{l}\text { Age at outcome: } 35-59 \\
\text { Age at exposure: } 20-44 \\
\end{array}$} & \multicolumn{2}{|c|}{$\begin{array}{l}\text { Age at outcome: } 60-79 \\
\text { Age at exposure: } 45-64\end{array}$} & \multicolumn{2}{|c|}{$\begin{array}{l}\text { Age at outcome: } 80+ \\
\text { Age at exposure: } 65+\end{array}$} & \multicolumn{3}{|c|}{ Overall } \\
\hline & $M$ & $F$ & $M$ & $F$ & $M$ & $F$ & $M$ & $F$ & Total \\
\hline oral cavity, pharynx & 840 & 164 & 1153 & 221 & 93 & 23 & 2086 & 408 & 2493 \\
\hline esophagus & 187 & 22 & 337 & 35 & 25 & 5 & 549 & 62 & 611 \\
\hline colon & 88 & 35 & 280 & 81 & 43 & 12 & 412 & 128 & 540 \\
\hline rectum & 118 & 31 & 313 & 67 & 36 & 8 & 467 & 106 & 573 \\
\hline liver & 52 & 13 & 135 & 33 & 15 & 4 & 201 & 51 & 253 \\
\hline larynx & 294 & 27 & 603 & 44 & 41 & 2 & 938 & 73 & 1011 \\
\hline breast (female) & - & 925 & - & 785 & - & 63 & - & 1772 & 1772 \\
\hline total & 1580 & 1218 & 2821 & 1266 & 252 & 116 & 4653 & 2599 & 7252 \\
\hline
\end{tabular}


young women (age at exposure 20-44 years old), number of alcohol-related cancer cases in middle-aged women (35-59 years old) is the highest.

\section{Discussion and conclusions}

Obtained results are similar to other studies in relation to the population of women and lower in men. For comparison, Scoccianti et al. [3] showed estimated alcohol attributable cancer burden in the Europe at the level of 3\% of all cancer cases for women and $10 \%$ in men. In our study it was respectively $3.4 \%$ and $5.8 \%$. One of the possible reasons in the differences in alcohol-related cancer burden among men could be the applied latency period. Moreover, alcohol consumption in Poland in 2002 was much lower than those observed currently [6].

The results obtained confirmed also a great impact of alcohol consumption on breast cancer occurrence. Considering solely women's population, about 10\% (1772) of all breast cancer cases (18 615) were attributable to alcohol consumption. Although Schutze et al. [11] in own studies indicated that alcohol-related breast cancer cases in 8 investigated European countries (France, Italy, Spain, United Kingdom, the Netherlands, Greece, Germany, Denmark) constituted about 2-8\%, what may suggest differences in alcohol consumption burden in the Polish women's population and in mentioned European countries.

Despite the fact that we conducted our study using simplified assumptions, the estimated cancer burden attributable to the alcohol consumption in Poland in 2016 is, without a doubt, significant for health of the Polish population. In the face of constantly growing alcohol intake in the Polish society [6], there is a need to implement public health actions on reducing strong cancer risk factors such as alcohol consumption.

\section{Limitations of the study}

Availability of the detailed data on alcohol consumption and drinking patterns in Poland is very limited. Data on alcohol drinking that we have used are based on 2443 questioners. Additionally, considered alcohol attributable cancers are also caused by different cofactors (for example joint smoking and drinking or HPV infection). Moreover, the reported data on the number of cancer cases in Poland are still burdened with some inadequacy.

Conflict of interest: none declared

\section{Paweł Koczkodaj}

Maria Skłodowska-Curie Institute - Oncology Center

Department of Epidemiology and Cancer Prevention

ul. Wawelska $15 B$

02-034 Warszawa, Poland

e-mail:pawel.koczkodaj@coi.pl

Received: 30 Oct 2019

Accepted: 25 Nov 2019

\section{References}

1. Testino $G$. The burden of cancer attributable to alcohol consumption. Maedica (Buchar). 2011; 6 (4): 313-320.

2. Grundy A, Poirier AE, Khandwala F et al. Cancer incidence attributable to alcohol consumption in Alberta in 2012. CMAJ Open. 2016; 4 (3): E507-E514.

3. Scoccianti C, Cecchini M, Anderson AS et al. European code against cancer 4th edition: alcohol drinking and cancer. Cancer Epidemiol. 2016; 45: 181-188.

4. BagnardiV, Rota $M$, Botteri E et al. Alcohol consumption and site-specific cancer risk: a comprehensive dose-response meta-analysis. Br J Cancer. 2015; 112: 580-593.

5. Meadows GG, Zhang $\mathrm{H}$. Effects of alcohol on tumor growth, metastasis, immune response, and host survival. Alcohol Res. 2015; 37 (2): 311-322.

6. The State Agency for the Prevention of Alcohol-Related Problems in Poland (PARPA). Research and statistical information, statistics. http:// www.parpa.pl/index.php/badania-i-informacje-statystyczne/statystyki [in Polish], accessed October $1^{\text {st }} 2019$.

7. The State Agency for the Prevention of Alcohol Related Problems. Alcohol and society. Attitudes and behaviours to alcohol and alcohol problems. Warsaw: State Agency for Prevention of Alcohol Related Problems. 2002.

8. Stare SM, Jozefowicz JJ. The effects of environmental factors on cancer prevalence, rates and specific cancer mortality rates in sample of OECD developed countries. International Journal of Applied Economics. 2008; 5 (2): 92-115.

9. Corrao G, Bagnardi V, Zambon A et al. A meta-analysis of alcoho consumption and the risk of 15 diseases. Preventive Medicine. 2004; 38 (5): 613-619.

10. Hamajima N, Hirose K, Tajima K et al. Alcohol, tobacco and breast cance - collaborative reanalysis of individual data from 53 epidemiological studies, including 58,515 women with breast cancer and 95,067 women without the disease. Br J Cancer. 2002; 87 (11): 1234-1245.

11. Schütze $M$, Boeing $H$, Pischon $T$ et al. Alcohol attributable burden of incidence of cancer in eight European countries based on results from prospective cohort study. BMJ. 2011; 342. 